\title{
Transient Hyperinsulinism
}

National Cancer Institute

\section{Source}

National Cancer Institute. Transient Hyperinsulinism. NCI Thesaurus. Code C131030.

Hyperinsulinism that resolves spontaneously. This is the most common cause of neonatal hypoglycemia. 